\title{
Characterization of Cellular Responses Involved in Reparative Dentinogenesis in Rat Molars
}

\author{
R.N. D'Souza", T. Bachman ${ }^{1}$, K.R. Baumgardner ${ }^{2}$, W.T. Butler, and M. Litz
}

Department of Basic Sciences, Room 4.133 F, and ${ }^{1}$ Division of Endodontics, Department of Stomatology, University of Texas at Houston Health Science Center, 6516 John Freeman Avenue, Houston, Texas 77030; ${ }^{2}$ Department of Cariology, Restorative Sciences and Endodontics, University of Michigan, Ann Arbor, Michigan (formerly with the Department of Endodontics, College of Dentistry, University of Iowa, Iowa City, Iowa); "to whom correspondence and reprint requests should be addressed

\begin{abstract}
During primary dentin formation, differentiating primary odontoblasts secrete an organic matrix, consisting principally of type I collagen and non-collagenous proteins, that is capable of mineralizing at its distal front. In contrast to ameloblasts that form enamel and undergo programed cell death, primary odontoblasts remain metabolically active in a functional tooth. When dentin is exposed to caries or by operative procedures, and when exposed dentinal tubules are treated with therapeutic dental materials, the original population of odontoblasts is often injured and destroyed. The characteristics of the replacement pool of cells that form reparative dentin and the biologic mechanisms that modulate the formation of this matrix are poorly understood. Based on the hypothesis that events governing primary dentinogenesis are reiterated during dentin repair, the present study was designed to test whether cells that form reparative dentin are odontoblastlike. Cervical cavities were prepared in rat first molars to generate reparative dentin, and animals were killed at various time intervals. In situ hybridization with genespecific riboprobes for collagen types I and III was used to study de novo synthesis by cells at the injured dentin-pulp interface. Polyclonal antibodies raised against dentin sialoprotein (DSP), a dentin-specific protein that marks the odontoblast phenotype, were used in immunohistochemical experiments. Data from our temporal and spatial analyses indicated that cells forming reparative dentin synthesize type I but not type III collagen and are immunopositive for DSP. Our results suggest that cells that form reparative dentin are odontoblast-like.
\end{abstract}

Key words: odontoblasts, reparative dentin, collagen, dentin sialoprotein, dental pulp.

Received June 10, 1994; Accepted October 21, 1994

\section{Introduction}

Primary odontoblasts are unique post-mitotic cells that, during tooth formation, are responsible for the synthesis and secretion of a specialized mineralized matrix called primary dentin. The differentiation of odontoblasts from a selected region of dental papilla ectomesenchyme is dependent on a series of epithelial-mesenchymal interactions that involve several growth factors and extracellular matrix (ECM) components (for review, see Thesleff $e t$ al., 1991, 1995). After withdrawing from the mitotic cycle, terminally differentiated odontoblasts establish polarity and develop morphologic features characteristic of matrix-producing cells. One of the earliest molecular changes that accompanies these events is the amplification of type I collagen synthesis and a downregulation in type III collagen production. Type I collagen is hence considered a major differentiation marker for functional odontoblasts, forming the principal structural component of organic dentin matrix.

In addition to collagen, terminally differentiated odontoblasts synthesize and secrete several non-collagenous proteins (NCPs) into the dentin ECM (Butler, 1995). A major $\mathrm{NCP}$ of rat dentin matrix is a sialic acid-rich glycoprotein or DSP (Butler et al., 1992). Immunohistochemical studies have shown that, during primary dentinogenesis, DSP is expressed by polarized odontoblasts that appear to transport the protein via their cytoplasmic extensions to the mineralizing front (D'Souza et al., 1992; Bronckers et al., 1993). Recently, a full-length rat DSP cDNA was cloned and sequenced (Ritchie et al., 1994); mRNA transcripts for the gene were observed only within odontoblasts involved in primary dentin formation (Ritchie et al., 1995). Although the precise role of DSP in the formation of dentin matrix is unknown, these findings show that DSP is synthesized and secreted exclusively by differentiated odontoblasts and establish that it is a valuable marker of terminal events that lead to primary dentin formation. Despite the recent progress made in our understanding of the molecular 
mechanisms that control odontoblast differentiation and function during primary dentinogenesis, little is known about the events leading to reparative dentin formation. This form of dentin is deposited at the dentin-pulp interface, directly beneath the path of injured dentinal tubules as a response to advancing dental caries, operative procedures, as well as therapeutic and restorative dental materials. In this study, we first establish the use of riboprobes to collagen types I and III and highly specific antibodies to DSP as valuable markers of odontoblast differentiation during primary dentinogenesis. We have further applied the use of these well-characterized markers of primary odontoblast differentiation to study the nature of cells in reparative dentinogenesis.

\section{Materials and methods}

\section{Operative procedures}

Outbred adult male Sprague-Dawley rats (Harlan SpragueDawley, Indianapolis, IN) weighing from 150 to $220 \mathrm{~g}$ were cared for with routine husbandry prior to and after surgery. Animals were anesthesized with a mixture of $80 \%$ Ketamine $\mathrm{HCl}$ (Parke Davis, Morris Plains, NJ) containing $20 \%$ xylazine (Rompun ${ }^{\circledR}$, Mobay Corporation, Shawnee, KS) injected intraperitoneally at a dose of $1.0 \mathrm{~mL} / \mathrm{kg}$, and then placed in a restraining device. Class V cavities were prepared on the mesial aspect of the maxillary and mandibular first molars to approximately half the distance through dentin, essentially as described by Taylor and Byers (1990). One molar in each animal was left untreated and served as a control. Cavities were left unrestored. At $6 \mathrm{~h}$ post-operative and on days $3,7,11$, and 14 after surgery, rats were killed by transcardial vital perfusion with $10 \%$ neutral-buffered formalin (NBF). The rationale for the post-operative time intervals of death was based on results of previous studies (Taylor and Byers, 1990).

\section{Tissue preparation}

Maxillary and mandibular segments were carefully blockdissected and fixed by immersion in $10 \%$ NBF for an additional $24 \mathrm{~h}$. After decalcification in buffered EDTA, tissues were processed routinely for paraffin embedding. Serial sections were then prepared in the para-sagittal plane and mounted on silane-coated slides; representative sections were stained with hematoxylin and eosin $(\mathrm{H} \& \mathrm{E})$. Sections from a total of 60 treated and 20 untreated first molars were evaluated. Those used for immunohistochemical and in situ hybridization experiments were selected from areas where the cavity floor was the deepest, so that the maximum pulpal response to injury could be evaluated.

For studies on the developmental appearance of DSP and collagen types I and III, alveolar segments containing molar tooth organs were dissected from rat pups at Days 1 and 2 of post-natal development. Tissues were fixed in 10\% NBF and processed for paraffin embedding without decalcification. Serial sections from 5 to $7 \mu \mathrm{m}$ thick were placed on silane-coated slides.

\section{Synthesis of riboprobes}

The $\alpha 2(\mathrm{I})$ collagen riboprobe was derived from a 200-bp PstIEcoRI segment coding for the COOH-terminal region of the rat pro $\alpha 2(\mathrm{I})$ collagen gene. After directional cloning into
Bluescript+ (Stratagene Inc., La Jolla, CA), plasmids were linearized downstream of the cDNA insert with either HindIII or EcoRI. Alpha 35S-UTP-labeled antisense and sense riboprobes were generated by $\mathrm{T} 7$ and $\mathrm{T} 3$ transcription systems, respectively. The $\alpha 1$ (III) antisense and sense mRNA probes were generated from a 333-nucleotide, EcoRV-SmaI segment corresponding to exon 52 of the murine pro $\alpha 1$ (III) collagen gene with T3 and T7 polymerases, respectively. Probed regions for both $\alpha 2$ (I) and $\alpha 1$ (III) collagen genes were selected outside of the region corresponding to the triple helix, to ensure minimal cross-hybridization with other collagen mRNAs. The specificity of these probes has been previously documented (Metäsaranta et al., 1991; Niederreither et al., 1992).

\section{In situ hybridizations}

After post-fixation in $4 \%$ formaldehyde, sections were pre-treated as described by D'Souza et al. (1993). Hybridizations were performed at high stringency with the denatured probes used at concentrations of $40 \mathrm{pg} / \mu \mathrm{L}$ in freshly prepared hybridization mix (50\% formamide, $0.3 \mathrm{M} \mathrm{NaCl}, 1 X$ Denhardt's solution, $10 \mathrm{mM}$ Tris, $5 \mathrm{mM}$ EDTA, $10 \%$ dextran, $10 \mathrm{mM}$ DTT, $10 \mathrm{mM} \mathrm{NaHPO}{ }_{4^{\prime}}$ $500 \mu \mathrm{g} / \mathrm{mL}$ yeast tRNA, and $200 \mu \mathrm{g} / \mathrm{mL}$ calf thymus DNA). Incubations were performed at $48^{\circ} \mathrm{C}$ overnight in a humidified chamber. After hybridization, sections were treated with RNase A $(20 \mu \mathrm{g} / \mathrm{mL})$ and RNase T1 $(1 \mu \mathrm{g} / \mathrm{mL})$ for $30 \mathrm{~min}$ at $37^{\circ} \mathrm{C}$, washed thoroughly, and then dipped in a 50\% mixture of NTB-2 photographic emulsion (Eastman Kodak Co., Rochester, NY) and $0.6 \mathrm{M}$ ammonium acetate. Slides were then autoradiographically exposed in a sealed box at $4^{\circ} \mathrm{C}$ for 4 or 5 days, developed, fixed, and lightly counterstained with hematoxylin.

\section{Immunohistochemistry}

Polyclonal antibodies raised to rat DSP were used in these experiments. Details on the isolation and characterization of rat DSP and the preparation and purification of the antibodies have been described earlier (Butler et al., 1992). For these experiments, polyclonal antibodies obtained from protocol 2 were used. These antibodies displayed high titers of about 1:15,000, as determined by ELISA, and were purified by passage through DSP and $\alpha 2 \mathrm{HS}$-glycoprotein affinity columns. The use of these antibodies to characterize the developmental appearance of DSP in developing rat molars has not been reported. For immunohistochemical staining, the $\mathrm{ABC}$-peroxidase method was used as reported earlier (D'Souza et al., 1992). Briefly, sections were deparaffinized and blocked sequentially with $0.6 \%$ hydrogen peroxide and $10 \%$ normal goat serum. Sections were then incubated with the primary antibodies to DSP at a 1:100 dilution at $4^{\circ} \mathrm{C}$ overnight in a humidified chamber. After several rinses in PBS, sections were reacted with biotinylated goat antirabbit IgG (1:200) for $1 \mathrm{~h}$ at room temperature and then treated with the avidin-biotin complex provided in the Vecta Elite kit (Vector Laboratories, Burlingame, CA). The immunostaining reaction was next developed in DAB (diaminobenzidine; Sigma Chemicals, St. Louis, MO) for from 3 to $7 \mathrm{~min}$, and sections were rinsed and lightly counterstained with Harris' hematoxylin. Control serial sections were treated with pre-immune rabbit antisera at a dilution of 1:200.

\section{Results}

The following observations were made following a careful 
Figure 1. Distribution of mRNA for collagen types 1 and III in rat maxillae at Day 1 of postnatal development. Bright-field $(a, c)$ and dark-field (b,d) illumination. $(a, b)$ High levels of $\alpha 2$ (I) collagen mRNA in terminally differentiated odontoblasts (large arrow) and in functional osteoblasts (arrowheads). Note the absence of hybridization in pre-odontoblasts (small arrow). (c,d) In contrast, gene transcripts for $\alpha 1$ (III) collagen are not visible in odontoblasts at the cusp tip (arrowhead). High levels of type III collagen transcripts are visible in mesenchymal cells of the dental papilla (dp), oral mucosa (om), and osteoblasts (arrowhead) within the alveolar crypt. Bars $=22 \mu \mathrm{m}$.
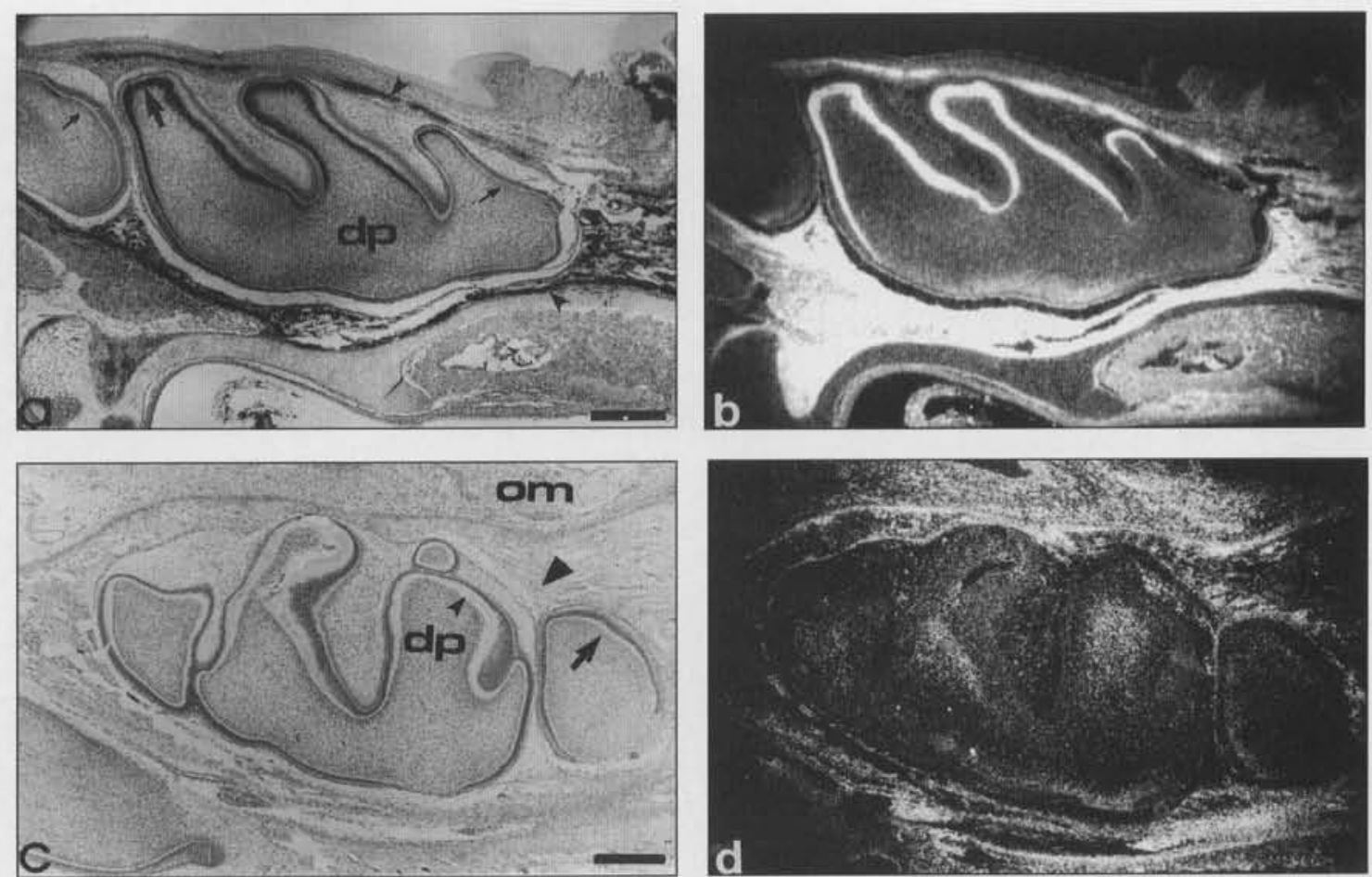

review of all serial sections treated in the hybridization and immunohistochemical experiments.

\section{Collagen types I and type III mRNAs show different patterns of expression during odontoblast differentiation (Fig. 1)}

We compared the distribution patterns of mRNA transcripts for $\alpha 2$ (I) collagen (Figs. 1a,b) and $\alpha 1$ (III) collagen (Figs. 1c,d) in developing rat molars at Day 1 of postnatal development. In the maxillary first molar tooth organ (Figs. 1a,b), the high level of expression of the type I collagen gene in newly differentiated odontoblasts (Fig. 1a, arrow) marks the differentiation of these cells from underlying dental papilla mesenchyme which, in contrast, shows weaker hybridization. Pre-odontoblasts (small arrows) located at the periphery of the dental papilla in the less-developed second molar and on the mesial cusp slopes of the first molar do not show the presence of $\alpha 2$ (I) collagen mRNA. Osteoblasts (arrowhead) in the surrounding alveolar crypt show strong hybridization to the $\alpha 2$ (I) collagen probe. The distribution pattern of mRNA for $\alpha 1$ (III) collagen in the less-developed second molar appears restricted to newly differentiated odontoblasts (arrow in Fig. 1c). As dentin formation progresses, pro- $\alpha$ (III) transcripts are less intensely expressed in odontoblasts at the cusp tips of the first molar (arrowhead), while mRNA levels were still detectable in cells of the dental pulp (dp). The connective tissue in the surrounding follicle (large arrowhead) and oral mucosa (om) showed high levels of type III collagen gene expression. Control sections treated with sense riboprobes to $\alpha 2$ (I) and $\alpha 1$ (III) collagens showed an absence of hybridization (data not shown).

\section{DSP is expressed by differentiated odontoblasts and} related pulp cells during tooth development (Fig. 2)

Immunostaining for DSP is visible in young odontoblasts that have come into contact with the basement membrane at the distal cusp tip of the first molar at Day 2 of postnatal development (Fig. 2a). The intracellular pattern of staining appears localized within the perinuclear area of odontoblasts (od) in the region of the golgi (arrow). Fig. 2b illustrates the developmental appearance of DSP in the region of the cusp groove. Immunostaining is lacking in preodontoblasts (po) at the base of the groove but first becomes visible in young odontoblasts prior to the initial deposition of mineral, as has been reported earlier (D'Souza et al., 1992; Bronckers et al., 1993). A diffuse pattern of staining is present in dental pulp mesenchyme (dp) and in clusters of pre-ameloblasts (Fig. 2b, arrowhead), but there are no immunoreactive cells in stellate reticulum (sr). Immunoreactive DSP is also visible in the distal mineralizing front of dentin (arrow in Fig. 2c) and is intense in secretory odontoblasts (od) at the mesial cusp tip. With this antibody preparation, there was a consistent lack of immunostaining in surrounding alveolar bone $(\mathrm{ab})$.

\section{Replacement cells aligning experimentally induced reparative dentin are immunoreactive for DSP (Fig. 3)}

In a molar not subjected to operative procedures, normal or resting odontoblasts (od) lining physiologic secondary dentin (pd) are immunoreactive for DSP (Fig. 3a), indicating that these cells are metabolically active in a normal adult tooth. Disruption of the layer of odontoblasts lining the dentin-pulp interface directly beneath the base of the cavity preparation is evident $6 \mathrm{~h}$ after surgery (Fig. 3b). DSP immunoreactivity is visible within disrupted cells and matrix in this area (arrows). Three days after surgery (Fig. $3 c)$, the integrity of the cellular layer at the dentin-pulp interface is re-established, and DSP immunostaining is 

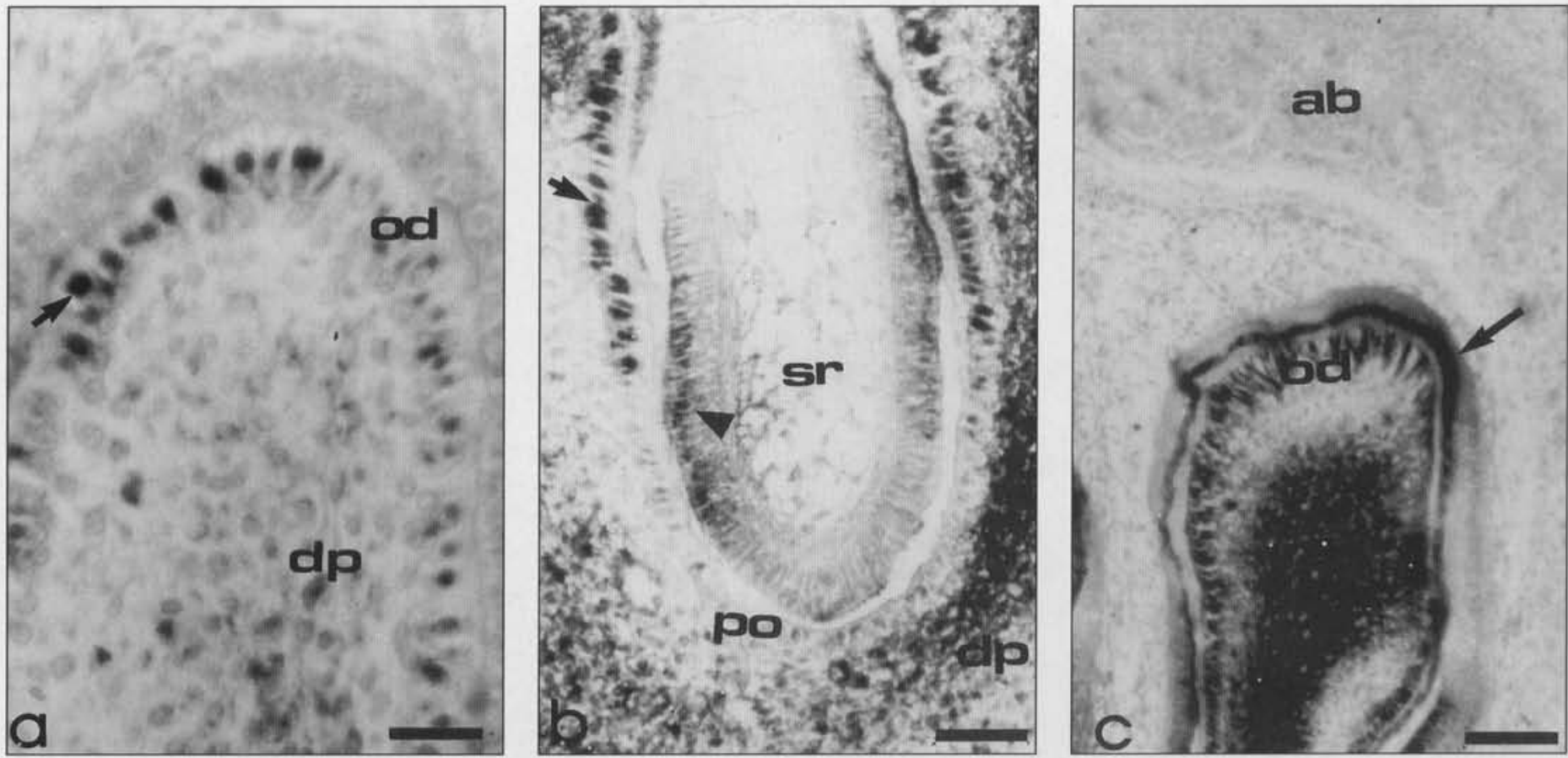

Figure 2. Developmental patterns of immunolocalization of DSP in developing molars at Day 2 of postnatal development. (a) Immunoreactive DSP in the golgi region of newly differentiated odontoblasts at the cusp tip of the second molar. A few dental papilla (dp) cells appear immunostained. (b) Pre-odontoblasts (po) at the base of a cuspal groove in a first molar do not express DSP, while mature odontoblasts (arrow) are positive for DSP. Several differentiating ameloblasts (arrowhead) are immunopositive, and dental pulp (dp) is immunostained. The stellate reticulum (sr) and other tissues in the molar organ are non-reactive. (c) DSP is not present in alveolar bone (ab) overlying the molar germ. The protein appears within secretory odontoblasts (od) and in the zone of mineralizing dentin (arrow). Bar in (a) = $23 \mu \mathrm{m}$. Bars in (b) and (c) $=46 \mu \mathrm{m}$.

visible in replacement cells in this region (arrow). Seven days after surgery, a distinct matrix is visible (Figs. $4 a$, c), and DSP immunostaining is retained in cells aligning the matrix (data not shown). Fig. 3d illustrates the full thickness of reparative dentin matrix formed 11 days after cavity preparation. This zone of repair (rd) is clearly distinguishable from physiologic dentin (pd) at the calcio-traumatic line (small arrows). Immunoreactive DSP is seen in cells (large arrow) aligning this irregular matrix. At higher magnification (Fig. 3e), the zone of reparative dentin nearest the calcio-traumatic line is seen to resemble osteodentin, similar to that described by Magloire et al. (1992). DSP immunoreactivity is visible in cellular inclusions and within the matrix (arrowhead). A few tubular extensions of DSP-positive cells (large arrow) are visible within the zone of reparative dentin more proximal to dental pulp. At po Day 14, a similar pattern of DSP immunostaining was visible within and around the zone of reparative dentin (data not shown). Fig. $3 \mathrm{f}$ is a control section treated with matching protein concentrations of pre-immune rabbit serum. Note that the hematoxylin staining reaction separates the more mineralized distal zone $(\star)$ from the lesscalcified proximal zone ( $(\hat{s})$.

The $\alpha 2$ (I) collagen gene is transcriptionally active in cells associated with reparative dentin, in contrast to the inactive $\alpha$ (III) collagen gene (Fig. 4)

In photomicrographs through a demineralized section through the center of the cavity preparation, gene transcripts for $\alpha 2(\mathrm{I})$ collagen are clearly visible in replacement cells (Figs. 4a,c; solid arrows) that have regenerated a zone of reparative dentin. Note that the undisturbed layer of original odontoblasts on either side of the zone of injury (Fig. 4a; open arrow) shows type I collagen synthesis and is continuous with cells involved with reparative dentin formation. More intense hybridization is seen in primary odontoblasts lining the coronal and apical walls of dentin, in contrast to odontoblasts lining lateral walls of circumpulpal dentin. Moderate signal intensity is visible in some cells of the dental pulp (Figs. 4c,d). We did not detect any hybridization signal in replacement cells within adjacent sections incubated with antisense $\alpha 1$ (III) collagen riboprobes (Figs. $4 \mathrm{e}, \mathrm{f})$. Serial sections treated with the sense $\alpha 1$ (III) collagen riboprobes showed no specific hybridization.

\section{Discussion}

This study assessed the molecular and biochemical characteristics of the cell population associated with experimentally induced reparative dentin formation in rat molars. The operative procedures of cavity preparation used in this study elicited pulpal responses that were similar to those described by other investigators (Weider et al., 1956; Taylor and Byers, 1990; Ohshima, 1990; Byers and Taylor, 1993; Fitzgerald, 1994). Exposure of dentinal tubules resulted in disruption of the odontoblastic and subodontoblastic zones at the affected interface, and we 
Figure 3. Immunohistochemical appearance of DSP in cells at the injured dentin-pulp (D-P) interface. (a) Immunoreactive DSP in mature 'resting' odontoblasts (od) at an undisturbed interface in a control molar. Dentinal tubules within physiologic dentin (pd) appear immunostained. (b) Six hours after the operative procedure, there is no DSP in involved tubules within pd and a loss of cellularity at the D-P interface (arrows). Moderate immuno-staining for DSP is visible in this region. (c) At 3 days, DSP-positive cells (arrow) are seen lining the D-P interface subjacent to the base of the cavity. (d) At 11 days, a defined layer of reparative dentin matrix is delineated from physiologic dentin (pd) at the calciotraumatic line (small arrows). Replacement cells aligning the rd matrix are clearly DSP-immunopositive. (e) At higher magnification, the zone of reparative matrix (rd) nearest the immunostained secondary dentinal tubules (arrow) shows immunostaining for DSP in matrix and in cellular inclusions (arrowhead). The large arrow points to DSP within replacement cells. $(f)$ Absence of DSP immunostaining in a serial section treated with pre-immune rabbit antiserum. ( $\star$ ) distinguishes the more mineralized zone of reparative dentin from the less mineralized area ( $\vec{\nabla})$. Bars in $a$, $\mathrm{b}, \mathrm{c}$, and $\mathrm{d}=46 \mu \mathrm{m}$; bars in $\mathrm{e}$ and $\mathrm{f}=23 \mu \mathrm{m}$.

observed that in all injured teeth, contiguity was reestablished at the involved dentin-pulp interface by the third post-operative day. This finding and the presence of a distinct reparative dentin matrix by po day 7 (Figs. 4a,c,e) are significant observations that confirm the findings of Byers and Taylor (1993), suggesting that, following injury and exposure of dentin to the oral environment, the pulp responds predictably by the formation of reparative dentin.

Data from our developmental studies further suggest the use of RNA probes to $\alpha 2$ (I) and $\alpha 1$ (III) collagens and antibodies to DSP as valid markers of odontoblast differentiation during primary dentin formation. Levels of $\alpha 2$ (I) collagen mRNA increased as odontoblast differentiation progressed. In contrast, type III collagen gene expression decreased in odontoblasts as dentinogenesis proceeded but remained significantly higher in dental pulp mesenchyme. The finding of $\alpha 1$ (III) collagen mRNA in newly differentiated odontoblasts (Figs. 1c,d) is consistent with recent data from other laboratories suggesting that odontoblasts both synthesize and secrete type III collagen
(Nagata et al., 1992; Lukinmaa et al., 1993). These results contradict earlier reports of studies, where less stringent techniques were used, that stated that odontoblasts do not express type III collagen at the mRNA or peptide level (Lesot et al., 1981; Andujar et al., 1991, 1988). Nevertheless, the differential patterns of mRNA distribution for these two matrix genes suggest that transcriptional regulatory mechanisms unique to odontoblasts may drive terminal differentiation events. Together, these data support the hypothesis that type I collagen is a major gene product of differentiated odontoblasts, while type III collagen is more dominantly expressed in mesenchymal cells of the dental pulp and follicle. In all serial sections studied, cells engaged in reparative dentin matrix expressed high levels of $\alpha 2(\mathrm{I})$ collagen mRNA but did not express $\alpha 1$ (III) collagen mRNA, lending support to our overall hypothesis that developmental events are repeated during repair. In these experiments, positive controls of developing maxillae were used to confirm that the negative hybridization seen with the $\alpha 1$ (III) collagen probe was a true finding. Our data are in 

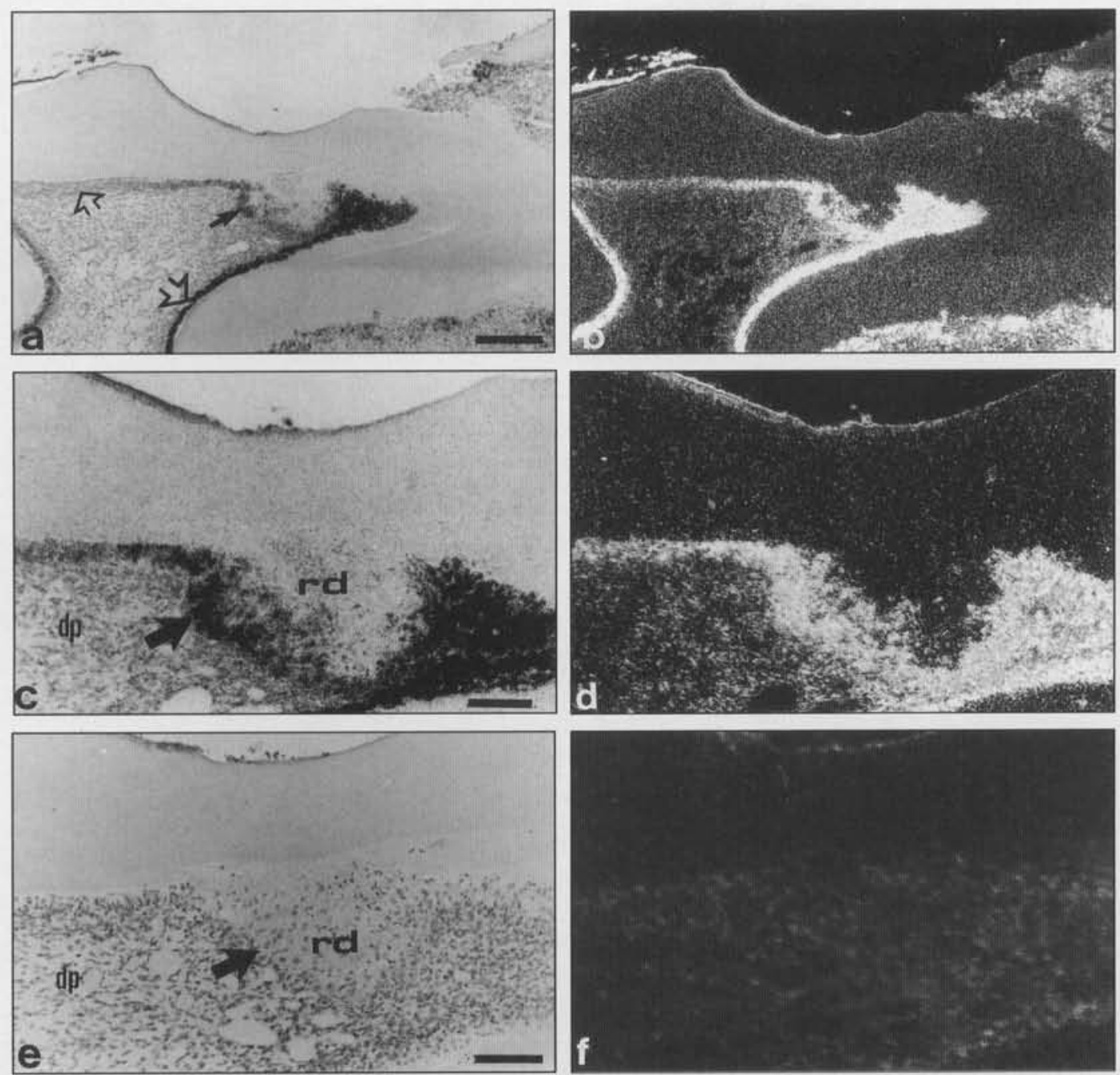

Figure 4. Differential patterns of expression of mRNAs for $\alpha 2(\mathrm{I})$ and $\alpha 1$ (III) collagen at the reparative dentin-pulp interface 7 days after cavity preparation. Sections were photographed under bright-field $(a, c, e)$ and dark-field (b,d,f) illumination. $(a, b)$ High levels of type I collagen mRNA in the population of cells (arrow) that are nearest reparative dentin. Open arrow points to hybridization within mature odontoblasts lining the floor of the pulp chamber. (c,d) At higher magnification, dominant levels of $\alpha 2$ (I) collagen mRNA are visible in the contiguous layer of cells (arrow) adjacent to reparative dentin (rd). Weaker hybridization is evident in pulpal cells (dp). Note that the level of signal intensity is directly proportional to the level of cellular density in this view. $(e, f)$ In an adjacent section, matrix-producing cells (arrow) do not express mRNA for $\alpha 1$ (III) collagen. Faint levels, slightly above the background hybridization seen in $\mathrm{rd}$, are evident in pulpal cells. Data from positive controls with developing maxillae are shown in Figs. 1c and $\mathrm{d}$. Bars in $\mathrm{a}$ and $\mathrm{b}=43 \mu \mathrm{m}$; bars in $c, d$, e, and $f=107 \mu \mathrm{m}$. agreement with those from recent in situ hybridization studies on human carious teeth that showed a lack of $\alpha 1$ (III) mRNA in cells aligning the newly deposited dentin matrix (Lukinmaa et al., 1993). Thus, the presence of immunoreactive type III collagen in reparative dentin formed beneath active carious lesions (Magloire et al., 1989; Lukinmaa et al., 1993) is puzzling. It is likely that type III collagen is rapidly synthesized in early phases of tissue repair, as has been suggested by investigators studying other wound-healing models (Holund et al., 1982; Williams et al., 1984).

Our results also show that DSP is a specific biochemical marker of functional odontoblasts. The presence of immunoreactive protein in newly formed dental pulp and in no other connective tissue suggests that more than one species of DSP may exist. This is supported by the recent findings whereby Northern blot analysis of neonatal rat tooth organs showed the presence of multiple transcripts of the gene (Ritchie et al., 1994; Butler, 1995). Studies are under way to elucidate the molecular basis of these observations. We found immunoreactive DSP in the undisturbed layer of metabolically active primary odontoblasts and within the matrix of secondary dentin. The finding of DSP in the cells and matrix of reparative dentin lend further support to the hypothesis that, in non-exposed pulps, reparative dentin is formed by odontoblast-like cells.

Since our studies did not utilize autoradiographic labeling techniques to assess cell migration and DNA replication events after cavity preparation, the questions related to the origin of reparative odontoblasts remain unanswered. It is likely that odontoblasts damaged by the operative procedures of cavity preparation used in these studies may have recovered and assumed functions of repair. This theory is supported by data from the ultrastructural and autoradiographic analyses performed on similarly treated rat molars (Chiego, 1992). In these studies, cells beneath the involved dentinal tubules showed ultrastructural changes characteristic of cell injury, but there was no evidence of cell death. Other studies on cell migration and replication events after cavity preparation show loss of integrity of the original odontoblast layer. Two theories on the origin of the cell population that replaces damaged odontoblasts have been proposed: The first supports the existence of a pre-determined odontoblastic population of cells derived from the cell-rich zone in the periphery of dental pulp (Torneck and Wagner, 1980; Ruch, 
1984; Veis et al., 1984). The other theory proposes that replacement cells that migrate to the site of injury originate from the core of coronal pulp, and that this pool is derived either from pulpal fibroblasts or vasculature or from resident undifferentiated mesenchymal cells (Fitzgerald, 1979; Yamamura et al., 1980; Fitzgerald et al., 1990). To date, however, no studies have evaluated the nature of the cell population responsible for the formation of reparative dentin.

Our studies demonstrate that the cells responsible for the synthesis and secretion of reparative dentin are odontoblastlike. Recent advances in the field have shown that odontoblasts synthesize at least two other dentin-specific proteins in addition to DSP: the phosphophoryns (Butler $e t$ al., 1983; Sabsay et al., 1991), and a recently characterized serine-rich phosphoprotein, AG-1, recently re-named DMP-1 (George et al., 1993). Antibodies and probes to these odontoblast-specific products can be used in similar approaches for further characterization of the cells and matrix of reparative dentin. Such approaches will also prove valuable in studies aimed at characterizing the cellular events involved in reparative dentin formation after treatment with growth factors such as bone morphogenetic protein -7 or OP-1, a member of the transforming growth factor-beta supergene family (Rutherford et al., 1993). Finally, information gained from in vivo studies on reparative dentinogenesis can provide the basis for in vitro experiments designed to evaluate the responses of cultured pulp cells to various dental materials.

\section{Acknowledgments}

We are grateful to Dr. Margaret R. Byers for her efforts in training Dr. Baumgardner in the use of the operative procedures described in these studies and for her critical comments regarding this manuscript. The assistance of Mr. Arturo Rodriguez in the preparation of the photographic plates is also acknowledged.

This research was supported by NIDR Grants DE-10517 (RND), DE-00175 (KRB), and DE 05092 (WTB) from the National Institutes of Health, Bethesda, MD 20892. A portion of the work described in this paper is based on a thesis project performed by Dr. Timothy Bachman.

\section{References}

Andujar MB, Hartmann DJ, Emonard H, Magloire H (1988). Distribution and synthesis of type I and type III collagens in developing mouse molar tooth root. Histochemistry 88:131-140.

Andujar MB, Couble P, Couble M-L, Magloire H (1991). Differential expression of type I and type III collagen genes during tooth development. Development 111:691-698.

Bronckers ALJJ, D'Souza RN, Butler WT, Lyaruu DM, van Dijk S, Gay S, Wöltgens JHM (1993). Dentin sialoprotein: biosynthesis and developmental appearance in rat tooth germs in comparison with amelogenins, osteocalcin and collagen type-1. Cell Tissue Res 272:237-247.

Butler WT (1995). Dentin matrix proteins and dentinogenesis. Proceedings of the Vth international conference on tooth morphogenesis and differentiation, May 4-8, 1994, Kerkrade, The Netherlands. Wöltgens JHM, Bronckers
ALJJ, Lyaruu DM, editors. Connect Tissue Res 32(1) (in press).

Butler WT, Bhown M, DiMuzio MT, Cothran WC, Linde A (1983). Multiple forms of rat dentin phosphoproteins. Arch Biochem Biophys 225:178-186.

Butler WT, Bhown M, Brunn JC, D'Souza RN, Farach-Carson MC, Happonen R-P, et al. (1992). Isolation, characterization and immunolocalization of a 53-kDal dentin sialoprotein (DSP). Matrix 12:343-351.

Byers MR, Taylor PE (1993). Effect of sensory denervation on the response of rat molar pulp to exposure injury. J Dent Res 72:613-618.

Chiego DJ (1992). An ultrastructural and autoradiographic analysis of primary and replacement odontoblasts following cavity preparation and wound healing in the rat molar. Proc Finn Dent Soc 88(Suppl 1):243-256.

D’Souza RN, Bronckers ALJJ, Happonen RP, Doga DA, FarachCarson MC, Butler WT (1992). Developmental expression of a $53 \mathrm{kD}$ dentin sialoprotein in rat tooth germs. I Histochem Cytochem 40:359-366.

D'Souza RN, Niederreither K, deCrombrugghe B (1993). Osteoblast-specific expression of the alpha-2(I) collagen promoter in transgenic mice: correlation with the distribution of TGF-B1. J Bone Min Res 8:1127-1236.

Fitzgerald M (1979). Cellular mechanics of dentinal bridge repair using 3H- thymidine. J Dent Res 58:2198-2206.

Fitzgerald M (1994). Autoradiographic temporal and spatial analysis of pulpal wound healing in the rat molar (abstract). J Dent Res 73:317.

Fitzgerald M, Chiego DJ, Heys DR (1990). Autoradiographic analysis of odontoblast replacement following pulp exposure in primate teeth. Arch Oral Biol 35:707-715.

George A, Sabsay B, Simonian PAL, Veis A (1993). Characterization of a novel dentin matrix acidic phosphoprotein. Implications for induction of biomineralization. J Biol Chem 268:12624-12630.

Holund B, Clemmensen I, Junker P, Lyon H (1982). Fibronectin in experimental granulation tissue. Acta Pathol Microbiol Immunol Scand 90:159-165.

Lesot H, Osman M, Ruch JV (1981). Immunofluorescent localization of collagens, fibronectin and laminin during terminal differentiation of odontoblasts. Dev Biol 82:371381.

Lukinmaa P-L, Vaahtokari A, Vainio S, Sandberg M, Waltimo J, Thesleff I (1993). Transient expression type III collagen by odontoblasts: developmental changes in the distribution of pro- $\alpha 1$ (III) and pro- $\alpha 1(\mathrm{I})$ collagen mRNAs in dental tissues. Matrix 13:503-515.

Magloire H, Joffre A, Hartmann DJ (1989). Localization and synthesis of type III collagen and fibronectin in human reparative dentine. Histochemistry 88:141-149.

Magloire H, Bouvier M, Joffre A (1992). Odontoblast response under carious lesions. Proc Finn Dent Soc 88(Suppl 1):257274.

Metasäranta M, Toman D, deCrombrugghe B, Vuorio E (1991). Specific hybridization probes for mouse type I, II, III and IX collagen mRNAs. Biochim Biophys Acta 1089:241-243.

Nagata K, Huang YH, Ohsaki Y, Kukita T, Nakata M, Kurisu K (1992). Demonstration of type III collagen in the dentin of mice. Matrix 12:448-455. 
Niederreither K, D'Souza RN, deCrombrugghe B (1992). Minimal DNA sequences that control the cell lineagespecific expression of the pro $\alpha$ 2(I) collagen promoter in transgenic mice. J Cell Biol 119:1361-1370.

Ohshima H (1990). Ultrastructural changes in odontoblasts and pulp capillaries following cavity preparation in rat molars. Arch Histol Cytol 53:423-438.

Ritchie HH, Hou H, Veis A, Butler WT (1994). Cloning and sequence determination of rat dentin sialoprotein, a novel dentin protein. J Biol Chem 269:3698-3702.

Ritchie HH, Hou H, Pinero G, Butler WT (1995). Molecular analysis of rat dentin sialoprotein. Proceedings of the Vth international conference on tooth morphogenesis and differentiation, May 48, 1994, Kerkrade, The Netherlands. Wöltgens JHM, Bronckers ALJJ, Lyaruu DM, editors. Connect Tissue Res 32(1) (in press).

Ruch JV (1984). Tooth morphogenesis and differentiation. In: Dentin and dentinogenesis. Linde $\mathrm{A}$, editor. Boca Raton, FL: CRC Press, pp. 447-479.

Rutherford RB, Wahle J, Tucker M, Rueger D, Charette M (1993). Induction of reparative dentine formation in monkeys by recombinant human osteogenic protein-1. Arch Oral Biol 38:571-577.

Sabsay B, Stetler-Stevenson WG, Lechner JH, Veis A (1991). Domain structure and sequence distribution in dentin phosphophoryns. Biochem J 276:699-707.

Taylor PE, Byers MR (1990). An immunocytochemical study of the morphological reaction of nerves containing calcitonin gene-related peptide to microabscess formation and healing in rat molars. Arch Oral Biol 35:629-638.
Thesleff I, Partanen A-M, Vainio S (1991). Epithelialmesenchymal interactions in tooth morphogenesis: The roles of extracellular matrix, growth factors and cell surface receptors. J Craniofac Genet Dev Biol 11:229-237.

Thesleff I, Vaahtokari A, Kettunen P, Aberg T (1995). Epithelialmesenchymal signalling during tooth development. Proceedings of the Vth international conference on tooth morphogenesis and differentiation, May 4-8, 1994, Kerkrade, The Netherlands. Wöltgens JHM, Bronckers ALJJ, Lyaruu DM, editors. Connect Tissue Res 32(1) (in press).

Torneck CD, Wagner D (1980). The effect of a calcium hydroxide liner on early cell division in the pulp subsequent to cavity preparation and restoration. $J$ Endocrinol 6:719-723.

Veis A, Tsay T-G, Kanwar Y (1984). An immunological study of the localization of dentin phosphophoryns in the tooth. INSERM 125:223-232.

Weider SR, Schour I, Mohammed CI (1956). Reparative dentine following cavity preparation and fillings in the rat molar. Oral Surg 9:221-232.

Williams IF, McCullough KG, Silver IA (1984). The distribution of type I and III collagen and fibronectin in the healing equine tendon. Connect Tissue Res 12:211-227.

Yamamura T, Shimono M, Koike H, Terao M, Tanaka Y, Sakai $Y$, et al. (1980). Differentiation and induction of undifferentiated mesenchymal cells in tooth and periodontal tissue during wound healing and regeneration. Bull Tokyo Dent Coll 21:181-222. 